\title{
APPLICATION OF CLOUD COMPUTING BASED ON E-LEARNING TEACHING TOOL
}

\author{
A.G.R.F Shereen \\ Assistant Lecturer, Department of Business and Communication Studies, Faculty of Communication and Business \\ Studies, Eastern University of Sri Lanka, Trincomalee Campus. \\ (B.Tech, MSc(Reading))
}

\begin{abstract}
The demand for cloud computing has pressured the development of new market offerings, representing various cloud services and delivery models. These models significantly expand the range of available options and tasks.Cloud computing allows changes in businesses and organizations with more choices regarding how to run infrastructures, save costs, and delegate liabilities to thirdparty providers. It has become an integral part of technology and business models, and has forced businesses to adapt to new technology strategies. Now Cloud computing introduces efficient scale mechanism which let the construction of E-Learning systems to be entrusted to all suppliers and provide a new mode for E-Learning.
\end{abstract}

Keywords : Cloud Computing, E-Learning, CloudE-Learning

\section{INTRODUCTION}

Development of the technology has made several changesin every field. Cloud computing is such a technology, which changed the traditional way of learning and accessing the data in more efficient way. It enables the environment to consume compute resources as a utility. Mainly there are so many benefits for both end users and businesses, such as self-service provisioning which enables end users can turn up computing resources for almost any type of work load on-demand. ."Pay-as-use" allowing users to pay only for the resources and workloads they use. Today many organizations and businesses are stepping towards this latest trend of using cloud services. This paper, describes about 1 . Services of E-learning based on cloud computing. 2. Cloud models used. Cloud computing into an E-learning systems and its structure to build a sustainable and flourishing Elearning.

\section{SERVICES OF E-LEARNING BASED ON CLOUD COMPUTING}

Cloud computing maintains the storage resources as services. Services provided by cloud computing can be classified into three main categories.
a) Software as a Service (SaaS)
b) Platform as a Service(PaaS)
c) Infrastructure as a Service(IaaS)

\subsection{Software as a Service (SaaS)}

This means Software deployed over the internet. It facilitates the use of different software applications by the end user over the internet. This facility has become a common within every organization among users and buyers of understanding the technology and what SaaS is and where to use it .Advantages of using SaaS is Software can be managed by central location, it delivered in one to many model, web access to commercial software. Users are not required to handle upgrading and patching. Simply access and managed software via a network.

\subsection{Platform as a Service (PaaS)}

Intermediate layer between SaaS and IaaS. It can be defined as a computing platform which allows the construction of web applications quickly and easily and without the complexity of buying and maintaining the software and infrastructure underneath it. It is a set of tools and services designed to make coding and deploying those applications quick and efficient. Advantages as Multi-level architecture, where multiple concurrent users utilize the same application. Services to develop and maintain,test, deploy and host the application in the same environment.

\subsection{Infrastructure as a Service (IaaS)}

It's the common way of delivering the cloud computing Infrastructure. such as servers, storage, operating systems, Hardware, Data, Database and network on demand. Advantages as All the resources are distributed as service, allow dynamic scaling, include multiple users on a single piece of hardware.

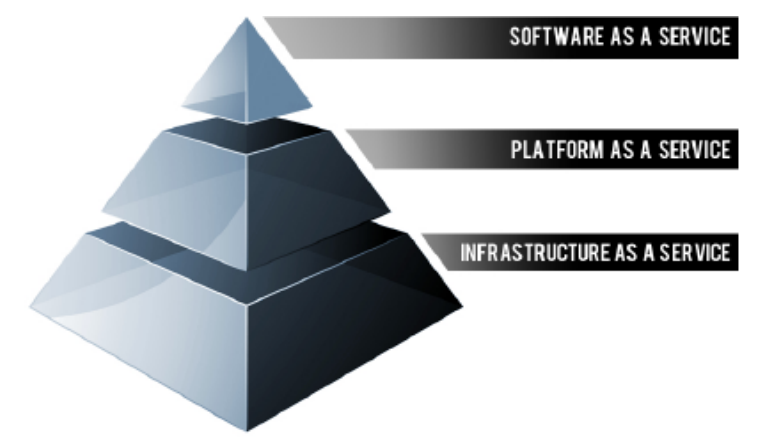




\section{CLOUD MODELS USED}

Based on the requirements Cloud computing models are defined.

\subsection{Public Cloud}

Service provides on public network engaging with local or public support. The entire resources and data hub is transparent to the end user. Public access of shared resources is provided in the distribution.

\subsection{Private Cloud}

Service provided in public services is dedicated to only for particular users to making it private to them. This model facilitates the organizations being owned by a particular section with more efficiently to manage their corporate data. The data is more secured in this type because only a certain user's access it and its safe placed under private cloud.

\subsection{Common Cloud}

Community based model specifically a particular set of users deployed on a common cloud. Mainly considered as a public service where it designed mainly for a group of people who work together.

\subsection{Hybrid Cloud}

Combination ofdifferent deployment models to make a dynamic and more efficient way to share the resources. Mostly it comes under the organizations which outsource the data.

\section{SYSTEM ARCHITECTURE}

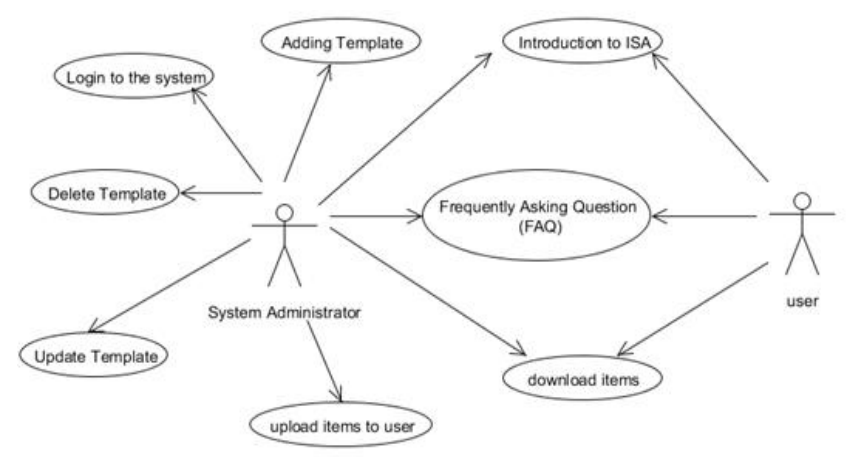

This section describes the architecture of this system. The complete system is sub modules into four modules. (A) Introduction module, (B) Templates module, (C) Question Answering module and (D) Download module. Each module is described in detail in the following subsections.

E-learning cloud is the cloud computing technology, where future learning infrastructure including all hardware and software computing resources to engage in e-learning.

\section{A. Introduction Module:}

This contains a brief introduction of the Instruction Set
Architecture and some detail explanation of the overall flow of implementation and how to use it. Hence it includes all kind of architectures and operations.

\section{B. Templates Module:}

To expand it and to obtain flexibility, whenever system overcomes a new question the administrator feels free to add a particular question and automatically the system generates the template, as well as answers, and to update the answer whenever it's, required but should follow the standard syntax when developing the templates.

\section{Question Answering Module:}

Using generic methods answer can be generated. When it does the statistical techniques it checks with

- Word resemblance

- Distance similarity

- Sentence length similarity

- Word order similarity

This assigns values to reflect the similarity. The sum of these values is used for comparison. This approach works rather poorly for short questions and when the query and FAQ use different wording to carry the same meaning, here when we use the Template matching approach, the templates are matched against the question asked by users. The success of the question answering thus depends a lot on the quality of these templates.

\section{Download Module:}

This facilitates users to download the related ISA Architectures and the other useful documents.

Here in this web based system Cloud E-learning is more efficient such as planning, implementation, execution and management.E-leaning will use the cloud computing server, so that all the resources they need can be adjusted when necessary.

\section{LITERATURE SURVEY}

a. In the research of Jain and Chawla they commonly considered about the advantages of cloud computing services in E-learning systems, providing architectural design concept of the system based on Cloud computing models have been studied, but their performance has been implemented according to plan the proposed architecture has been evaluated [1].

b. In Gamundani's research Cloud based E-learning system is described and system architecture developed. This proposed architecture although the elastic characteristics of the specific features of Cloud computing architecture will provide all the characteristic features in high precision [9].

c. Pocatilu, implemented an E-learning system based on the cloud computing architecture is described and only the advantages and positive effects of using cloud computing technology in the field of E-learning is discussed[10]. 


\section{ADVANTAGES OF CLOUD BASED E- LEARNING}

There are lot of advantages in E-leaning implementation of cloud computing technology, such as,

\section{1) Least cost}

Configuration of each Pc is not needed, all can cloud the application through PC, mobile phone, tablet PC with a internet connection. Here they only pay for the storage that they acquire.

\section{2) Benefit for both students and lecturers}

In the sphere of students they can do online exams, courses and post assignment, projects. Can receive the feedback from lecturers too. As well as Lecturers can post assignments, test, take home assignments so in brief both students and lecturers can have online line contact through cloud.

\section{3) Updates are always available}

In cloud-based applications e-learning parallel run with automatically updated software. So the learners receive it always.

\section{4) Security}

Information and data are secured here with high precision. Both the software and the data are stored on remote server can get crash or vanish without any warning. Cloud computing provides some major security benefits for developing E-learning solutions.

\section{5) Higher availability}

In any time any environment E-learning is convenient for students. It considered as learner-centred approach which is difference among lecturers and they can check there confidence level of the materials.

\section{CONCLUSION}

Cloud computing feed positives in various ways with higher beneficial. Such as maintains storage capacity, cost effectiveness, software updating and ease of access and all over complete availability.it can be developed and integrated with any other utilizable teaching tools to work more and more for E-learners.

\section{REFERENCES}

[1] Jain, A and S.Chawla, "E-learning in the cloud "International Journal of Latest Research in Science and Technology 2 (1): 478-481, 2013

[2] http://www.menumate.com/

[3] http://trineo.co.nz/

[4] http://diversity.net.nz/wpcontent/uploads/2011/01/Movi ng-to-the-Clouds.pdf

[5] http://diversity.net.nz/wpcontent/uploads/2011/01/Moving-to-the-Clouds.pdf
[6] http://aws.amazon.com/

[7] http://www.rackspacecloud.com/index.php

[8] http://m.zdnet.com/blog/forrester/is-the-iaaspaas-linebeginning-to-blur/583

[9] Gamundani , A.M T. Rupere "A Cloud computing architecture for E-learning platform, supporting media content " International Journal of Computer Science and Information Security 11(3).2013

[10] PocatiluP,FAlecu and M Vetrici "Using Cloud computing E-learning Systems." Recent advances on data networks, communications, Computers": proceedings of $8^{\text {th }}$ WSEAS International Conference on Data Networks, Communications, Computers, Italy 2009 